\title{
THE ELUSIVE VIRGINIA RAIL
}

MABEL CHARLTON, 501 McGillivray Dr., Weyburn, Saskatchewan. S4H 1L9

Rails prefer to escape from an intruder through well worn runways in the sedges, rather than trust their short, rounded wings. The shy, skulking hiders make their way in and out of the cattail mazes over the oozy ground with wonderful rapidity, or at least so I found this past summer when I tried to photograph a nesting female rail.

John Whittel found the nest as he shagged golf balls in a natural stream-like body of water on the Weyburn golf course. Virginia Rails are rather rare birds in our area and our local natural history society

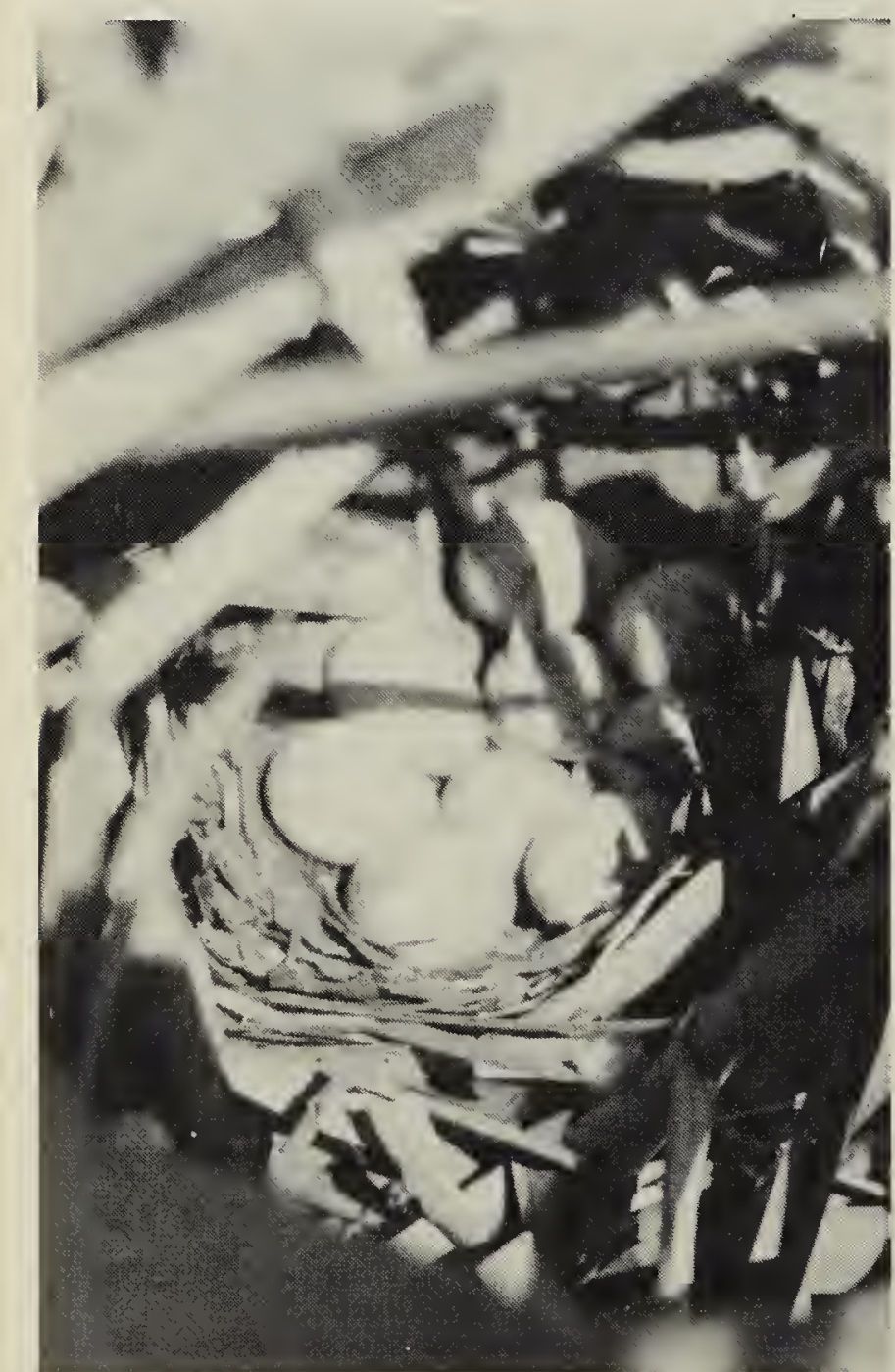

Virginia Rail nest.

Mabel Charlton members were excited about the find. John told us there was a nest in much the same spot the summer before. He watched it carefully but didn't say too much about it then.

In the summer of 1992, on the bird's return, John decided to get a positive identification and some pictures for proof. He asked me if I would try to get the pictures. I put on John's rubber boots and with camera, lenses and flash, I waded out (trying not to damage the natural camouflage) as close to the nest as possible.

A battle of wits began. That elusive little bird with its narrow-breasted, wedge-shaped body so quickly forced her way through the grassy, cattail jungle that it was impossible for me to get a clear picture. She made certain there was always plenty of tangle between us. If I got a little too near she would rise feebly, fluttering her wings, just above the tops of the rushes, her long legs dangling limply, then dropping down as if exhausted. A good diver, she could disappear completely. A time or two I saw her clinging to a stout, sturdy stem, submerged, with only her reddish bill above the water. A swift swimmer too, she could get out of range quickly. She was in her own safe territory. In John's rubber boots, I was hardly able to turn, let alone move. If I stood too long and patiently in the same motionless position, I was stuck in the mud.

Interesting birds these rails. Food gathered from the ground is picked 
off with sharp pecks. Rails can run up the rushes also, clinging there with the help of their hind toes on the swaying stem, and get seeds, insects or berries at the top. Their long, front toes, flattened but scarcely lobed, enable them to tread out a dinner from the mud. Beetles, small crustaceans and small forms of water invertebrates as well as grasshoppers, are favourite foods.

The nest was built on a mound of cattail stems and grasses, on the ground at the marshy, muddy, sodden edge of the water. It was well hidden among tall cattails and wild willows. It seemed almost to have a dome or kind of cover and was full of eggs. The eggs were pale, creamy white, speckled with brown.

It was easy to get a picture of the nest, but I did worry that I might cause the female to desert. The male came when she called but stayed well out of range and was very secretive.

Rails' meat was (maybe still is) considered a delicate, gourmet food. Such a pitifully small, thin body re- quired the cooks to pluck dozens for one meal, thus the expression "thin as a rail."

Rails make only short, weak flights on seemingly feeble wings, yet they may migrate from the West Indies to Hudson Bay. So their flight is not at all as feeble as it appears to be.

I wonder if the pair will return to the same spot for the third year. They did have a successful hatch. I wonder if I will have better luck getting a picture.

Maybe I should try a blind - but maybe not, we don't want them to abandon that perfect nesting site. Maybe I should take along a pocket comb to attract the rails, as scratching the teeth of a comb produces a sound like the rail's call. Maybe that would bring one close.

I am much intrigued with these small, shy birds. They are more often heard than seen. They are so seldom seen that they are virtually unknown. Very few articles and good photographs have appeared in publications.

\title{
EXTRAVAGANT NEST DEFENSE - UNLIKELY TO PAY OFF
}

\begin{abstract}
A. J. (TONY) ERSKINE, Canadian Wildlife Service, Box 1590, Sackville, New Brunswick. EOA $3 \mathrm{CO}$
\end{abstract}

Defense of nests or broods is potentially risky, exposing the parent bird as well as its eggs or young to a predator. When defense is prolonged in time or space or both, it risks attracting other predators besides the one that set off the reaction. If such behaviour occurs in most individuals of a species, we infer that benefits of defense outweigh the costs. With species in which nest defense is not usual, such behaviour may be no more than individual aberration. 